\title{
Erythrocyte Indices and Leucocyte Count of Children with Plasmodium Falciparum Infection in Yola, Nigeria
}

\author{
Emmanuel Asuquo Etim*1, Adjekuko Ohwonigho Collins², Ahmadu Buba Usman ${ }^{3}$ and Jacob \\ Nwonoba Nweke ${ }^{4}$ \\ ${ }^{1}$ Department of Hematology, Federal Medical Centre Yola, Adamawa State, Nigeria \\ ${ }^{2}$ Department of Medical Laboratory Services, General Hospital Asaba, Delta State, Nigeria \\ ${ }^{3}$ Emergency Pediatric Unit, Federal medical center Yola, Adamawa State Nigeria
}

${ }^{4}$ Department of Hematology, Faculty of clinical sciences, Ambrose Alli University, Ekpoma, Edo state

*Corresponding author: Emmanuel AsuquoEtim, Department of Hematology, Federal Medical Centre, Yola, Adamawa State, Northeast Nigeria

\section{ARTICLE INFO}

Received: 幽 August 03, 2020

Published: 慧 August 12, 2020

Citation: Emmanuel Asuquo Etim, Adjekuko Ohwonigho Collins, Ahmadu Buba Usman, Jacob Nwonoba Nweke. Erythrocyte Indices and Leucocyte Count of Children with Plasmodium Falciparum Infection in Yola, Nigeria. Biomed J Sci \& Tech Res 29(3)-2020. BJSTR. MS.ID.004809.

Keywords: Erythrocyte Indices; Leucocyte Count; Plasmodium Falciparum

Abbreviations: RDW: Red Cell Distribution Width; MCV: Mean Cell Volume; MCH: Mean Cell Hemoglobin; MCHC: Mean Cell Hemoglobin Concentration; RBC: Red Blood Cell; HCT: Hematocrit; WBC: White Blood Cell; RDW-CV: Red Cell Distribution Width Coefficient of Variation;

\section{ABSTRACT}

Background/Objectives: Plasmodium falciparum malaria is the commonest cause of childhood mortality in Africa with varied hematology consequences hence, this study aims to evaluate erythrocyte indices of children with P. falciparum infection in other to elucidate infant's erythrocyte condition during falciparum infection.

Materials and Methods: 243 subjects participated in this study comprising 124 (71females and 53males) experimental group with mean age of $24 \pm 3.8$ months and 119 (68females and 51males) controls group with mean age of $27 \pm 6.1 \mathrm{months} .2 \mathrm{ml}$ of venous blood were collected from participants into K3-EDTA vacutainer. Erythrocyte indices and leucocyte counts were determined within 4 hours of blood collection using Sysmex XN550 hematological analyzer.

Results: Erythrocyte count of subject with P. falciparum infection was $2.63 \pm 0.9 \times 10^{12} / \mathrm{l}$ while Erythrocyte level of control group was $4.31 \pm 0.8 \times 10^{12} / 1$ at $\mathrm{P}<0.05$. RDW-CV of subjects was $16.5 \pm 0.1 \%$ while RDW-CV of control was $13.2 \pm 0.9 \%$. Hemoglobin level of subject and control was $6.9 \pm 1.1 \mathrm{~g} / \mathrm{dl}$ and $12.3 \pm 1.2 \mathrm{~g} / \mathrm{dl}$ respectively and MCV of subject was $86.7 \pm 1.3 \mathrm{fl}$ while that of the control group was $75.3 \pm 1.0 \mathrm{fl}$. MCH of control and subject groups were $25.8 \pm 0.5 \mathrm{pg}$ and $26.2 \pm 0.2 \mathrm{pg}$ respectively and the value of MCHC of subjects was $30.3 \pm 0.6 \mathrm{~g} / \mathrm{dl}$ while MCHC of control group was $33.9 \pm 0.4 \mathrm{~g} /$ $\mathrm{dl}$ at $\mathrm{P}<0.05$. Total leucocyte count of subjects and control group were $7.13 \pm 0.4 \times 10^{9} / \mathrm{l}$ and $8.9 \pm 1.6 \times 10^{9} / 1$ respectively and neutrophil counts of children with P. falciparum infection was $3.94 \pm 0.2 \times 10^{9} / \mathrm{l}$ while neutrophil count of control was $3.5 \pm 2.9 \times 10^{9} / \mathrm{l}$.

Conclusion: Children with Plasmodium falciparum infection in Yola had higher MCV and RDW-CV values with lower erythrocyte count, hemoglobin and MCHC value and no significant difference in leucocyte counts when compare with control group.

surgery it is frequently of interest to measure different parameters simultaneously. The goal of this work was to find an optimal system for this purpose and to build up a multichannel temperature measuring system. We selected a highly flexible system, which also provides Ethernet compatibility in conjunction with relatively easy development of specific software. Specifically, the temperature measurement component was realized with Pt-1000 sensors, which were connected to the base in four-wire link. First tests after calibration showed stable and reproducible values over a long time period. The system works well, and it can be adapted in a way to allow measurements of further physical parameters in the near future. 


\section{Introduction}

Erythrocyte indices are parameters that examine red blood cell conditions and measures the size, shape, and physical characteristics of erythrocytes[1] and erythrocyte indices are usually part of routine automated full blood count test which measures our general health. In pediatric medicine however, erythrocyte indices constitute important hematological parameters useful in clinical care of children[2] and erythrocyte indices are frequently overlooked in clinical practice but they provide assistance in establishing diagnosis in many health problems including: inflammatory[3] and anemic conditions[4]. Erythrocyte indices considered in this study are: RDW (Red Cell Distribution Width), MCV (Mean Cell Volume), MCH (Mean Cell Hemoglobin) and MCHC (Mean Cell Hemoglobin Concentration). MCV is a measure of the average size of red blood cell and MCH is a calculation of the average amount of hemoglobin inside a red blood cell, while MCHC is a measure of the average concentration of hemoglobin in the RBCs and Red Cell Distribution Width (RDW) is an automated measure of variation in red blood cell sizes and RDW is usually calculated by dividing the standard deviation (a measure of variation) of RBC volume by MCV and multiply by 100 . A large RDW indicates abnormal variation in red cell size. In this study however, Erythrocyte indices will be measures with Red Blood Cell (RBC) count and Hematocrit (HCT) and the clinical implications of determining red cell indices along with RBC count and HCT are that various type of anemia can be detected, identify and differentiated in infant[2].

Human beings have an immune system that depends on different types of white blood cells for protection against diseases[5,6]. These white blood cells also called leucocytes include: Neutrophils, Lymphocytes, Monocytes, Basophils and Eosinophils. White blood cells are vital components of blood that help fight infection, foreign bodies and response to inflammatory and allergic processes. White Blood Cell (WBC) counts during malaria are generally characterized as being low or normal and WBC counts have been reported to be lower in patients infected with Plasmodium falciparum[7]. Plasmodium falciparum is a unicellular protozoan parasite of humans and human malaria are caused by any of several species of Plasmodium parasites that may occur together in various combinations in endemic regions. Plasmodium falciparum is responsible for almost all etiology and mortality attributed directly to malaria and P. falciparum is the focus of almost all research and interventional efforts[7] in sub-Saharan Africa. In Nigeria however, malaria parasitemia arising from plasmodium falciparum infection still remains a public health challenge[8] and malaria infection has a complex effect on physiology of erythrocyte as well as iron metabolism that may affect hemoglobin and serum ferritin and malaria is the commonest cause of childhood morbidity in Africa with varied hematology consequences[9] hence, this study aims to evaluate the erythrocyte indices and leucocyte count of children with P. falciparum infection in other to elucidate the general health condition of infant's erythrocyte and leucocyte during plasmodium falciparum infection.

\section{Inclusion Criteria}

Symptomatic and asymptomatic children less than 30months old in the hospital who had P. falciparum malaria infection with no hemoglobinopathy and other clinical diseases were recruited for this study.

\section{Exclusion Criteria}

Children more than 30months old who had hemoglobinopathies and other clinical disorders were excluded. In addition, children who were infected with other species of Plasmodium aside from falciparum were also excluded from this study.

\section{Materials and Methods}

This prospective and descriptive study was carried out at the hematology department of Federal Medical Center Yola in Adamawa State, Northeastern Nigeria. A total of 243 subjects participated in this study comprising 124 (female $=71$, male $=53$ ) children with mean age of $24 \pm 3$.8months who had P. falciparum malaria infection and 119 (female $=68$, male 51) apparently healthy children with mean age of $27 \pm 6.1$ months used as control group.

\section{Sample Collection}

$2 \mathrm{ml}$ of blood were drawn from convenient peripheral vein of children into K3-EDTA vacutainer tubes. The vacuum tubes were further labeled with child's number, sex, weight and age. The samples were used for Erythrocyte indices and leucocyte counts test and preparation of thick and thin blood smears for malaria parasite microscopy within 2 hours of collection. The values of red cell indices were obtained from the automated full blood count while plasmodium falciparum infection was detected using microscopy method and other clinical information was gotten from the medical record of subjects.

\section{Statistical Analysis}

Statistical analysis was performed using SPSS computer software version 20.0 (IBM Chicago, IL, USA). Descriptive values were given as mean and standard error of mean. Categorical variables were expressed as the number of cases and the percentage value. The Student's t-test was used to compare the means differences of the estimated parameters and all statistics were carried out at the probability level of 0.05 .

\section{Sample Analysis}

Erythrocyte Indices and Leucocyte Counts Determination: Using Sysmex XN550 hematology analyzer, the procedure for Erythrocyte indices and leucocyte counts determination was performed as follows: EDTA samples were placed in a blood mixer for three minutes and the blood cells were automatically counted 
through a probe fitted in the sysmex machine. After one minute, the result of the blood cell count was displayed on the colored LCD screen of the machine.

Malaria Microscopy: Blood smear was prepared using slide method[10] and stain with Field stains. Microscopic examination and presence or absence of Plasmodium falciparum malaria parasite were determined using standard methods.

\section{Results}

Sex distribution of subjects reveals that $88.1 \%$ of children infected with plasmodium falciparum were female while $65.7 \%$ were male and $60.7 \%$ and $80.9 \%$ of the control group were male and female respectively as shown in Tables 1 \&2.Analysis of red cell indices shows that mean red cell count of subject with P. falciparum infection was $2.63 \pm 0.9 \times 1012 / 1$ while red cell count of control group was $4.31 \pm 0.8 \times 1012 / \mathrm{l}$ at $\mathrm{P}<0.05$. In addition, Red Cell Distribution Width Coefficient Of Variation (RDW-CV) of subjects with falciparum infection was $16.5 \pm 0.1 \%$ while the RDW-CV of control was $13.2 \pm 0.9 \%$. Hemoglobin (HGB) level of subject and control was $6.9 \pm 1.1 \mathrm{~g} / \mathrm{dl}$ and $12.3 \pm 1.2 \mathrm{~g} / \mathrm{dl}$ respectively. In addition, mean Hematocrit (HCT) level of subjects was $22.8 \pm 0.7 \%$ while HCT

Table 3: Erythrocyte Indices and Leucocyte Count of Subjects. of control group was at $39.1 \pm 0.3 \%$. On the other hand, Mean Cell Volume (MCV) of subject was $86.7 \pm 1.3 f$ while that of the control group was 75.3 $\pm 1.0 \mathrm{fl}$. Furthermore, Mean Cell Hemoglobin (MCH) of control and subject groups were $25.8 \pm 0.5 \mathrm{pg}$ and $26.2 \pm 0.2 \mathrm{pg}$ respectively and the value of Mean Cell Hemoglobin Concentration (MCHC) of children with P. falciparum infection was $30.3 \pm 0.6 \mathrm{~g} / \mathrm{dl}$ while MCHC of control group was $33.9 \pm 0.4 \mathrm{~g} / \mathrm{dl}$ at $\mathrm{P}<0.05$ as shown in Table 3.

Table 1: Age and sex distribution of children with Plasmodium Falciparum Infection.

\begin{tabular}{|c|c|c|}
\hline AGE (Months) & $\mathbf{2 4 \pm 3 . 8}$ & \\
\hline SEX & Number Observed & Percentage \\
\hline Female: & 71 & 88.1 \\
\hline Male: & 53 & 65.7 \\
\hline
\end{tabular}

Table 2: Age and sex distribution of children without Plasmodium Falciparum Infection.

\begin{tabular}{|c|c|c|}
\hline AGE (Months) & $\mathbf{2 7 \pm 6 . 1}$ & \\
\hline SEX & Number Observed & Percentage \\
\hline Female: & 68 & 80.9 \\
\hline Male: & 51 & 60.7 \\
\hline
\end{tabular}

\begin{tabular}{|c|c|c|}
\hline Parameters & Erythrocyte Indices and Leucocyte Count of Subjects & Erythrocyte Indices and Leucocyte Count of Controls \\
\hline tWBC $\left(10^{9} / \mathrm{l}\right)$ & $7.13 \pm 0.4$ & $8.9 \pm 1.6$ \\
\hline $\mathrm{NEUT}\left(10^{9} / \mathrm{l}\right)$ & $3.94 \pm 0.2$ & $3.5 \pm 2.9$ \\
\hline $\mathrm{LYMPH}\left(10^{9} / \mathrm{l}\right)$ & $2.46 \pm 0.3$ & $4.1 \pm 2.7$ \\
\hline $\mathrm{MONO}\left(10^{9} / \mathrm{l}\right)$ & $0.70 \pm 0.01$ & $0.6 \pm 0.5$ \\
\hline $\operatorname{EOSIN}\left(10^{9} / \mathrm{l}\right)$ & $1.0 \pm 0.0$ & $0.5 \pm 0.3$ \\
\hline $\mathrm{BASO}\left(10^{9} / \mathrm{l}\right)$ & $0.02 \pm 0.0$ & $0.6 \pm 0.2$ \\
\hline $\mathrm{RBC}\left(10^{12} / \mathrm{l}\right)$ & $2.63 \pm 0.9$ & $4.31 \pm 0.8$ \\
\hline $\mathrm{HGB}(\mathrm{g} / \mathrm{dl})$ & $6.9 \pm 1.1$ & $12.3 \pm 1.2$ \\
\hline $\mathrm{HCT}(\%)$ & $22.8 \pm 0.7$ & $39.1 \pm 0.3$ \\
\hline $\mathrm{MCV}(\mathrm{fl})$ & $86.7 \pm 1.3$ & $75.3 \pm 1.0$ \\
\hline $\mathrm{MCH}(\mathrm{pg})$ & $26.2 \pm 0.2$ & $25.8 \pm 0.5$ \\
\hline $\mathrm{MCHC}(\mathrm{g} / \mathrm{dl})$ & $30.3 \pm 0.6$ & $33.9 \pm 0.4$ \\
\hline $\mathrm{RDW}-\mathrm{CV}(\%)$ & $16.5 \pm 0.1$ & $13.2 \pm 0.9$ \\
\hline
\end{tabular}

Evaluation of leucocyte count indicates that, mean Total White Cell Count (TWBC) of subjects and control group were $7.13 \pm 0.4 \times 109 / 1$ and $8.9 \pm 1.6 \times 109 / 1$ respectively and neutrophil (Neut) counts of children with $P$. falciparum infection was $3.94 \pm 0.2 \times 109 /$ lwhileneutrophil count of control was 3.5 $\pm 2.9 \times 109 / 1$. Analysis of lymphocyte (Lymph) count shows that subject had a mean lymphocyte count of $2.46 \pm 0.3 \times 109 / 1$ and the control group had a lymphocyte count of $4.1 \pm 2.7 \times 109 /$ l. Furthermore, monocyte (Mono) count of subject and control group was $0.70 \pm 0.01 \times 109 / 1$ and $0.6 \pm 0.5 \times 109 / 1$ respectively. Children with falciparum infection had eosinophil (Eosin) count of $1.0 \pm 0.0 \times 109 / 1$ while the eosinophil of control group was $0.5 \pm 0.3 \times 109 / 1$ and basophil (Baso) count of subjects and controls were $0.02 \pm 0.0 \times 109 /$ and $0.6 \pm 0.2 \times 109 / 1$ respectively as shown in Table 3 .

\section{Discussion}

Erythrocyte indices and leucocyte count of children with plasmodium falciparum infection in Yola have been analyzed, sex distribution of experimental group shows that, 71 (88.1\%) of children were females while 53(65.7\%) were males indicating the predominance of females' children over boys infected with P. falciparum in this study. The mean total red cell count of children with P. falciparum infection was $2.63 \pm 0.9 \times 1012 / 1$ while that of the control group was $4.31 \pm 0.8 \times 1012 / \mathrm{l}$ this shows that children with 
P. falciparum infection had a lower red cell count than the control group at $\mathrm{P}<0.05$ and this is because anemia has been reported to be a consequence of P. falciparum infection[11]. The hematocrit level and hemoglobin level in subject was lower than that of the control group which could imply presence of asymptomatic anemia arising from imbalance between production and destruction of red blood cell in children with falciparum malaria[12]. In addition, the RDW of children with P. falciparum infection was $16.5 \pm 0.1 \%$ while the RDW for control group was $13.2 \pm 0.9 \%$ and this higher value of RDW among subjects is a pointer to presence of anisocytosis in this group of children because RDW is a measure of size variance of RBCs[13]. Therefore, a low RDW suggests uniform red cell size, whereas an elevated RDW (greater than 14 percent) as observed in this study indicates RBCs of variable and multiple sizes (i.e anisocytosis) therefore, the red cell of infants investigated were of variance sizes. The MCV of infected children was higher than that of the control group and this implies that the RBC infected with plasmodium falciparum was larger in size than non-infected RBC in this study. There were no significant differences between total and differential white cell count of subject and control groups and the reason for this result is not yet clear but this observation is in variance with the earlier report by Ellis Mckenzie et al., who concluded in 2005 that white cell count in patients infected with P. falciparum and P. vivax were lower than non-infected group[7]. However, the values of leucocyte count between subjects and controls group as observed in this study is in conformity with the earlier report by Jadhav et al., at 2003 in India[14].

\section{Conclusion}

Children with Plasmodium falciparum infection in Yola had higher MCV and RDW-CV values with lower erythrocyte count, hemoglobin and MCHC value and no significant difference in leucocyte counts when compare with control group. It is believed that information provided in this study will help in understanding the erythrocyte status and improve the clinical care of children with Plasmodium falciparum infection in this locality.

\section{Disclaimer}

The views expressed in this article are that of the author(s) not an official position of any hospital or institution.

\section{Financial Sponsorship}

This study was not sponsored, the equipment used was provided by the hospital in which this work was done.

\section{Acknowledgement}

The authors are sincerely grateful to the management of Federal Medical Center Yola, for providing the environment and equipment for this research work.

\section{Previous Publication}

This article has not been submitted to any journal for publication except the one being considered now.

\section{Conflict of Interest}

There is no conflict of interest regarding this work among the authors.

\section{References}

1. Etim EA (2018) Effect of maintenance hemodialysis on red cell indices and erythrocyte sedimentation rate in Northeast Nigeria. ARC Journal of Hematology 3(1): 17-22.

2. Akodu SO, Njokanma OF, Adeolu KO (2015) Erythrocyte indices in pre-school Nigerian children with sickle cell anaemia in steady state. International Journal of Hematology-oncology and Stem Cell Research 9(1): 5-9.

3. Ositadinma IM, Ikponmwosa OS, Okechukwu OC (2015) Hematology and red cell indices in HIV positive individuals on anti-retroviral therapy in Delta State, Nigeria. International Journal of Current Research and Review 7(12): 24-30.

4. Terri A, Cavaliere MS (2004) Newborn and Infant Nursing Reviews. Journal Hematological Disorders 4(4): 321-329.

5. Johnson DW, Wiggins KJ, Armstrong KA (2005) Elevated white cell count at commencement of peritoneal dialysis predicts overall and cardiac mortality. J Kidney Int 67: 738-743.

6. Donato D, Dimitrios D, Nicholas C, Jana R, Karel R (2012) Effects of Hemodialysis on Activation of Lymphocytes: Analysis by an in Vitro Dialysis Model. J Am Soc Nephrol. 2: 1490-1497.

7. Mckenzie E, Prudhomme W, Magill A, Forney R, Permpanich B (2005) White blood cell counts and malaria. J Infect Dis 192(2): 323-330.

8. Okocha EC, Ibeh CC, Ele PU, Ibeh NC (2005) The prevalence of malaria parasitaemia in blood donors in a Nigerian teaching hospital. Journal of Vector Borne Diseases. 42(1): 21- 24.

9. Maina R, Walsh D, Gaddy C, Hongo G, Waitumbi J (2010) Impact of plasmodium falciparum infection on hematology parameters in children living in Western Kenya. Malaria journal 9(3): 1-4.

10. Tkachuk DC, Hirschmann JV (2007) Approach to the microscopic evaluation of blood and bone marrow. In: Wintrobe Atlas of clinical haematology. Williams \& Wilkins, Lippincott, USA.

11. (2006) Ministry of Health: National guidelines for diagnosis, treatment and prevention of malaria for health workers in Kenya. Division of Malaria Control, Ministry of Health. Kenya.

12. Irwin JJ, Kirchner JT (2001) Anemia in children. Am Fam physician 64(8): 1379-1386.

13. (2009) Pediatric Nutrition Handbook. $6^{\text {th }}$ edn. Elk Grove Village, Ill.: American Academy of Pediatrics; pp. 403-422.

14. Jadhav UM, Singhvi R, Shah R (2003) Prognostic implications of white cell differential count and white cell morphology in malaria. J Postgrad Med 49: 218-221. 
ISSN: 2574-1241

DOI: $10.26717 /$ BJSTR.2020.29.004809

Emmanuel Asuquo Etim. Biomed J Sci \& Tech Res

(c) (P) This work is licensed under Creative

Submission Link: https://biomedres.us/submit-manuscript.php

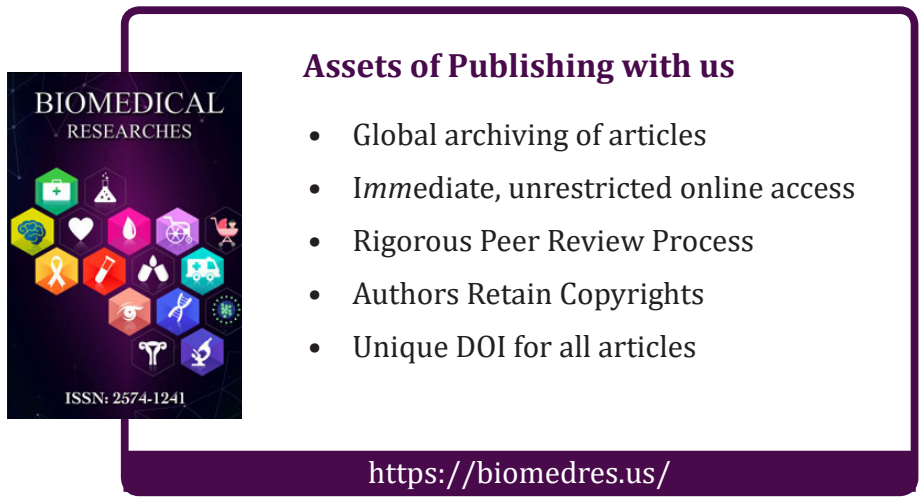

